\title{
Integrated care for childhood epilepsy: ongoing challenges and lessons for other long-term conditions
}

Authors: Amit Bali, Dougal S. Hargreaves, John Cowman, Monica Lakhanpaul, Colin Dunkley, Millie Power, J. Helen Cross

Dr Amit Bali, Clinical Leadership Fellow, Young Epilepsy, St Piers Lane, Lingfield, Surrey RH7 6PW, United Kingdom; Dr Dougal S Hargreaves, Clinical Senior Research Fellow/Honorary Consultant Paediatrician, PPP programme, UCL Institute of Child Health, 30 Guilford Street, London WC1N 1EH, United Kingdom; John Cowman, Director of Operations, Young Epilepsy, St Piers Lane, Lingfield, Surrey RH7 6PW, United Kingdom; Professor Monica Lakhanpaul, Programme Director - Integrated Children, Young People and Maternal Health Programme, UCL Partners, 170 Tottenham Court Road, London W1T 7HA, United Kingdom; Dr Colin Dunkley, Consultant Paediatrician, Sherwood Forest Hospitals NHS Foundation Trust, King's Mill Hospital, Mansfield Road, Sutton in Ashfield, Nottinghamshire NG17 4JL, United Kingdom; Millie Power, Service User, London, United Kingdom; Professor J Helen Cross, The Prince of Wales's Chair of Childhood Epilepsy and Honorary Consultant in Paediatric Neurology, UCL-Institute of Child Health, Great Ormond Street Hospital, London \& Young Epilepsy, St Piers Lane, Lingfield, Surrey RH7 6PW, United Kingdom.

Correspondence to: Dr Amit Bali (email: a.bali@ucl.ac.uk)

Keywords/phrases: 'epilepsy', 'integrated care', 'integration', health services', ' children and young people' 


\section{Integrated care for childhood epilepsy: ongoing challenges and lessons for other long-term conditions}

Authors: Amit Bali, Dougal S. Hargreaves, John Cowman, Monica Lakhanpaul, Colin Dunkley, Millie Power, J. Helen Cross

Epilepsy care has been identified as a major global issue - and there are many recognised concerns in the UK for children and young people with the condition. A proposed new model could help to increase multi-sector integration, facilitate better outcomes, and offer lessons for improving care of other long-term conditions.

The General Assembly of the World Health Organisation passed a resolution on the global burden of epilepsy last year highlighting the need for 'coordinated action at the country level to address its health, social and public knowledge implications'. This represented a welcome landmark in the global struggle to improve epilepsy treatment and reduce the associated stigma ${ }^{1}$. The resolution highlighted the challenges faced by health services in providing care for the 50 million people affected by epilepsy across the world. Due to shortages of medicines and appropriately trained doctors, fewer than $25 \%$ of individuals with epilepsy in low-income countries receive adequate treatment, which can completely control symptoms in up to $70 \%$ of cases. Further, widespread stigmatisation and discrimination mean that individuals in low, middle and high-income countries continue to face difficulties in education, employment, relationships and reproduction.

\section{Global progress and challenges in epilepsy care}

The approval of this resolution, however, also offers an opportunity to celebrate advances that have been made in recent years, with improvements in care as a result of new diagnostic techniques ${ }^{2}$ and anti-epileptic drugs, and a growing role for other treatments such as epilepsy surgery ${ }^{3}$ and the ketogenic diet ${ }^{4}$. There has also been progress towards addressing the stigma associated with epilepsy. In 1997, the WHO and partners launched the Global Campaign against Epilepsy (GCAE): 'Out of the Shadows ${ }^{5}$, , with the aim of improving 'acceptability, treatment, services and prevention of epilepsy worldwide'. A major focus of the campaign was addressing 'myths and superstitions,' and promoting public and professional understanding of epilepsy, as a universal, treatable brain disorder. They highlighted that a lack of understanding of epilepsy operates at all levels - including patients, health care professionals and policy makers - contributing to an under-estimation of the disease burden associated with epilepsy with under-treatment of patients.

Following the launch of the GCAE, several countries piloted projects to address stigma, understand the disease burden, and deliver effective epilepsy care at scale. For example, one project in China ${ }^{6}$ screened over 55,000 people and reported lifetime epilepsy prevalence of around 7/1000, almost 
double the previous best estimate. Since then, recognition and treatment of epilepsy has received substantial attention and resources from national policy makers, providing a model of evidencebased care, and improved quality of life for many patients at relatively little cost.

Lastly, the model of partnership working between patient and professional groups, and recognition of the role that social and cultural factors can play in successful medical treatment, make epilepsy care an exciting model for tackling wider health challenges. The WHO has identified noncommunicable diseases (NCDs), such as epilepsy, as the major cause of deaths worldwide, and called for a paradigm shift in NCD strategies, involving empowerment of people and communities, a human rights and equity-based approach, and multi-sectoral action ${ }^{7}$. Whether at local, national or international levels, epilepsy partnerships between patients/advocacy groups and health agencies have demonstrated the impact and cost-effectiveness of such strategies, offering lessons that can be applied across a wide range of conditions. While the priorities and context of epilepsy care varies widely between countries, a closer look at developments in the care of childhood epilepsies in the UK over the last two decades reveals very similar achievements, ongoing challenges and wider lessons for healthcare delivery.

\section{Key milestones in improving paediatric epilepsy care in the United Kingdom}

Epilepsy is one of the major long-term conditions (LTCS) affecting CYP, and is the most common neurological disorder in this age group. More than 1 in 200 children and young people under the age of 25 have epilepsy, with the total in the UK estimated at over $112,000^{8}$. However, the identified issues with epilepsy care do not only involve those with confirmed epilepsy, but also the process of diagnosis itself, with rates of incorrect diagnosis of epilepsy having been historically high. One study ${ }^{9}$ in 2006 found that up to $40 \%$ of CYP referred to specialist clinics eventually transpired not to have the condition. The corollary of this startling statistic is many of this group had been diagnosed and consequently inappropriately commenced on antiepileptic drug treatment. Yet, at the other end of the spectrum, there are a significant number of children who are not being adequately treated, with estimates that up to $70 \%$ of people with epilepsy could be free of seizures if appropriately managed ${ }^{8}$.

The reasons behind sub-optimal outcomes for children and young people are perhaps best understood by considering some of the seminal initiatives in epilepsy care over recent years. In the early 2000s, a well-publicised enquiry into practice at one hospital highlighted many of the intrinsic challenges of accurately diagnosing epilepsy in children, with over-diagnosis and the overprescribing of antiepileptic drugs ${ }^{10}$. Rather than problems with individual clinical assessment, however, the enquiry instead pinpointed systemic failings. This view was reinforced more widely in the National Sentinel Clinical Audit of Epilepsy-Related Deaths ${ }^{11}$, which uncovered specific shortcomings in access, quality of care and communication. In particular, therapeutic management was found to have been inadequate in almost $50 \%$, and $59 \%$ of deaths were felt could possibly have been avoided.

In response to such findings, the British Paediatric Neurology Association (BPNA) has led a comprehensive, long-term programme to improve outcomes through transforming the quality of epilepsy services. This started with the recognition of the fact that poor communication and a variation in access to investigations existed, and that resources were not being appropriately 
utilised $^{12}$. In 2003, the organisation published a report setting out an integrated model across primary, secondary, tertiary and quaternary healthcare. The report recommended improved access to specialists and appropriate investigations, better selection of eligible patients for surgical intervention, improved support for clinical networks, and a need for earlier social care and education involvement as the way towards improving care. It also emphasised the essential role of the epilepsy nurse specialists and proposed the creation of a new position - the paediatrician with 'an expertise in epilepsy'. These roles were reinforced by the launch of the Paediatric Epilepsy Training (PET) courses (www.BPNA.org.uk/PET), which became the gold standard for training in epilepsy; to date in excess of 5000 doctors and nurses have moved through these courses nationally ${ }^{13}$.

Another important step came with the introduction of national guidelines for childhood epilepsy care; ${ }^{1415}$, as well as providing recommendations regarding clinical practice, these have also outlined the model of what a 'good' epilepsy service should look like. The guidelines also acknowledged the wider effects of an epilepsy diagnosis, and made mention of a whole system approach. Unfortunately, making specific recommendations about mental health, education, social care and the third sector was beyond the scope of the guidelines at the time, and so a broader unified, national strategy did not form part of this none-the-less practical guidance. NICE went further still in 2013, publishing a valuable Quality Standard which described high priority areas ${ }^{16}$. Once again, however, whilst an integrated approach was recommended in the accompanying document, it was not reflected in the nine specific standards as the design methodology required them to be directly derived from the NICE recommendations.

\section{Evidence of the need to improve epilepsy care in the United Kingdom}

Mirroring the global picture described above, more recent data on the care of CYP with epilepsy in the UK continue to demonstrate significant ongoing concerns, albeit alongside some areas of major progress. For example, a 2013 report examining avoidable mortality and morbidity in childhood epilepsy ${ }^{17}$ found that $24 \%$ of studied deaths were potentially avoidable. Despite improvement in some areas, there was ongoing evidence of inadequate communication, service fragmentation and problems with assessment and classification. This report emphasised the importance of adhering to the now-established national guidelines, and also recommended a named paediatrician with appropriate expertise as a means to improve the coordination of care, the need for clear care plans, and involving families in management.

Concerns about the quality of epilepsy care have been backed up by findings in Epilepsy12. The first round of this national audit highlighted the presence of longstanding issues including misdiagnosis, poor communication and a variation in care ${ }^{18}$. Though the second round, published in 2014, found some improvement in its measured indicators, these same problems were continuing ${ }^{19}$ (Figure 1). By way of example, the proportion of paediatric services with an epilepsy specialist nurse has increased from $46 \%$ to $59 \%$. Some argue that this is good progress, but it remains the case that over one-third of paediatric services across the country do not contain a vital component of an adequate service.

It is clear therefore that, despite considerable action over a period of many years, the desired improvement has not been equitably seen across the UK. The difficulties encountered by many CYP 
are reflected in the experiences, of one of the authors of this article, MP, whose history is summarised in our case study (Figure 3). There remains a set of diverse barriers that need to be overcome, all of which require urgent attention in order to make further improvements. Two key factors would appear to be the persisting fragmentation of services, and limited success in developing genuine partnership working with children, young people and families.

\section{Focus on integration}

Epilepsy has a broad functional impact on CYP, at a vital point in their development - something which is being increasingly recognised, with growing evidence that even children with 'wellcontrolled' seizures can experience problems with learning and behaviour ${ }^{20,21}$. Any child with epilepsy may require input from a combination of agencies, including physical health, mental health, social care and education. Although fragmentation of these services has been acknowledged, few practical moves towards achieving integration have been initiated. This is surprising, given that such a model would be well suited to meeting the needs of CYP with epilepsy, bringing improved coordination of care and a whole-system approach ${ }^{22}$. However, recent UK policy developments, listed in Table $1^{23-24}$, promote many of the necessary conditions for integration to occur: leadership, a collaborative culture, financial incentives and accountability ${ }^{25}$. It is essential that an integrated approach is adopted in order to make further necessary improvements, and now appears to be the right time.

\section{A model for integrated epilepsy care for children and young people}

Importantly, CYP, parents and professionals have confirmed a shared appetite for integrated epilepsy care. A novel collaborative group (comprising a prominent academic institution, an Academic Health Science Network, a healthcare Trust working in both community and hospital settings, and - uniquely - a leading third sector organisation) has been working to address epilepsy care for CYP. Their recent qualitative work ${ }^{26}$ has combined existing evidence with the perspectives of these key groups, through focus groups, interviews and questionnaires, aiming to pinpoint barriers and enablers to improving outcomes. Thematic analysis uncovered four clearly identifiable enablers that would, taken together, enhance care: improving communication, better data, tailored care to meet individual needs, and a whole systems strategy.

This work highlighted the fragmentation of services that continues to perpetuate inadequate care, adding that use of these identified enablers would facilitate closure of the gap between current services and desired standards. The report went on to recommend specific innovative tools which, taken together, would act as a model towards achieving a truly integrated system (Figure 2). A key element of this is a national epilepsy registry which, when used alongside individualised care plans, would allow the use of up-to-date data to directly inform changes and adjustments in an individual's care. This would facilitate tailored care, reflecting that 'epilepsy' is an umbrella term for a heterogenous group of conditions (i.e. 'the epilepsies') and also the unique ways in which the condition impacts on each CYP and their family. A registry would also allow group data to be more easily and frequently collated than at present, enabling services to regularly audit relevant 
indicators, and commissioners to shape provision according to the true needs of their population, to the ultimate benefit of individual service users.

The co-creation of young people's networks, currently being piloted, will ensure young people and families are rightly placed at the centre of their care, having a true influence both on their own care and on wider service provision. This sits alongside recent national work to enhance existing regional epilepsy professional networks, such that best practice is shared and innovation spread. It is anticipated that this foundation of optimised communication will lead to the co-production of other formal tools to enhance communication, such as a shared electronic record. Lastly, the model recognises the overall need for a wider systems strategy, encompassing all relevant sectors to the care of CYP with epilepsy. Therefore an economic analysis that specifically determines the financial benefits and cost-effectiveness of a multi-sector approach has been commissioned, helping to support implementation of all of the tools, and in time leading to a 'year of care' tariff that properly represents the broad range of services involved.

Overall, this model acknowledges that every child or young person with epilepsy is different, with a unique combination of needs requiring input from different agencies. This proposed move to a person-centred, individualised approach would see services 'wrap-around' each CYP, with development of tailored plans encompassing all relevant agencies, and the success or failure being determined by meaningful outcomes. This requires a paradigm shift in epilepsy care with, for example, seizure freedom seen not as the end goal, but rather as one important outcome alongside others such as improved school attendance, educational attainment and gainful employment. Importantly, the model also recognises the overwhelming need to give CYP and families greater control over their condition.

It is clear to see how applying the model to our case study (Figure 3) could have addressed the four interlinked themes identified above and have improved her experience in several ways. First, improving communication between her, her family, and the medical and school teams working with her could have ensured that all relevant parties were aware of the support and care she needed from school, for example making them aware of how her seizures typically manifest, and setting out clear instructions for how staff should appropriately respond. This could have reduced the consequences of her epilepsy on school attendance and educational attainment, as well as minimised the emotional and social impact of epilepsy on her life. Second, an individualised care plan could have facilitated this cross-sectoral communication and helped establish shared goals and priorities between her, her family and all relevant professionals. Third, a whole-systems strategy could have reduced geographical variation in epilepsy services and ensured that appropriate structures were in place to support cross-sectoral working and participation of young people in improving epilepsy services. For example, young people's networks have been shown to be an effective tool to involve young people in shaping their care, contributing to improved outcomes ${ }^{27}$. Similar benefits could be anticipated for CYP with epilepsy, however there is wide variation in the availability of such opportunities between different areas. No such young people's network was available when MP could have benefitted from this support; indeed, she did not have any access to an epilepsy specialist nurse (who would often help coordinate such groups) through her time at secondary school. Lastly, taking part in an epilepsy registry could have ensured that more information on the educational, psychological and social impact of epilepsy was available to the professionals caring for MP. In addition, the registry could play a key role in investigating how 
health, educational, occupational and social outcomes can be improved for children and young people with epilepsy in the future.

\section{Lessons for other long-term conditions}

Whilst epilepsy, with its demonstrated effect on a young person's learning and behaviour, lends itself particularly well to a multi-sector integrated approach, there is also a clear role for better partnership-working in the other common LTCs of childhood. For example, there is evidence that poorly-controlled asthma or diabetes leads to lower school or college attendance, and these conditions therefore also have an educational and socio-economic impact. While the specific context will differ between conditions, the enablers of improved communication, better data, a tailored (individual) approach, and a unified national strategy offer a useful template for co-ordinated action to improve care of other long-term conditions. Equally, the concepts of person-centred care, and including the voice of CYP - key elements in our integrated model for epilepsy - are increasingly prioritised in wider health and care circles $^{28}$. We therefore anticipate the integrated model for epilepsy care will prove similarly invaluable in promoting optimal care for CYP in other LTCs.

\section{Conclusion}

Both global and UK strategies to support people with epilepsy have succeeded in making important achievements. However, as acknowledged recently by the WHO, epilepsy care worldwide continues to face challenges. In the UK, significant concerns remain about the quality and variation of care that is provided, with multiple sources over many years demonstrating persisting systemic failures. Our proposed model of integrated epilepsy care offers the opportunity to deliver more effective, person-centred, and efficient care through effective partnership working between CYP, families and professionals across health, educational, social care and voluntary sectors. We believe this approach may offer useful lessons for policy and practice development in other countries and different specialities, in particular for strategies to address the growing global burden of NCDs through patient empowerment and co-ordinated action across sectors.

\section{Key messages:}

- Despite a number of important improvements in diagnostic and treatment techniques in recent years, epilepsy care for children and young people remains a concern in the UK, as well as globally.

- In order to improve outcomes, a system-wide approach is needed that reflects the broad functional impact of epilepsy.

- There is a need to reduce fragmentation in epilepsy services for CYP, encompassing all sectors involved and working in partnership with CYP and families.

- A model towards achieving true integration has recently been developed, utilising tools that enable improved communication, better data, tailored care and a whole-system strategy. This offers a pathway for improving epilepsy care in other settings, and also for other long-term conditions. 


\section{Tables and figures}

Figure 1: \% Clinical Performance indicator results for Round 1 (2012) and Round 2 (2014), Epilepsy $12^{19}$. 'Whiskers' indicate $95 \%$ confidence intervals.

Table 1: Levers for an integrated system for epilepsy care in CYP

Legislation: The Children and Families Act 2014 delivered a legal requirement for education, social care and healthcare to work together and commission jointly. ${ }^{23}$

Political will: There were specific calls from cross-party MPs for greater integration in epilepsy care following the passing of the Children and Families Act 2014. This has been recently reinforced in a Backbench Debate on epilepsy. ${ }^{24}$

Health policy: The NHS Outcomes Framework includes a goal to improve the quality of life for people with long-term conditions, alongside a specific aim to reduce unplanned hospital admissions for young people with epilepsy. ${ }^{25}$ 
Figure 2: Model for integrated epilepsy care for CYP ${ }^{26}$ 
I had my first tonic-clinic seizure at 11 months, losing all use of my right side, and was diagnosed with tuberous sclerosis complex. Throughout my childhood my tonic-clinic seizures were well-controlled with medication, but I continued to have absence seizures.

Communication has always been an issue. At school, most teachers thought "seizures are just when people drop to the floor though aren't they?" If they had understood my seizures better then I wouldn't have missed so much school (60 days in 5 years), as I was needlessly sent home after each absence. I knew my condition best, and could judge if I was okay to stay at school, but instead my mother regularly had to leave work and pick me up. Equally, one of my seizure triggers is stress, and I would have more absences around exam periods. I was made to sit exams without any extra support, which I know would have helped me to do better if it was in place. Conversely, my doctors rarely asked about how my epilepsy affected me in day-to-day life. A better appreciation of this would have helped me get the care I needed at various points. What I needed most was a way for those caring for me to address the things that concerned me.

This was also true during transition, and with my adult neurologists. I had a tonic-clonic seizure at work (13 years after the last) and an 'urgent' neurology appointment was promised. I was really anxious and needed to speak with someone quickly, but did not get an appointment until 5 months later. Recently, I wanted to see a genetic counsellor to discuss issues around having my own family, but was told ' you're only 21 and don't need that now'. This isn't true, it's just frustrating. 


\section{Contributors and sources}

Dr Amit Bali, Clinical Leadership Fellow, Young Epilepsy; Honorary Research Associate, UCL Institute of Child Health, 30 Guilford Street, London WC1N 1EH

Dr Dougal S Hargreaves, Clinical Senior Research Fellow/Honorary Consultant Paediatrician, PPP programme, UCL Institute of Child Health, 30 Guilford Street, London WC1N 1EH

John Cowman, Director of Operations, Young Epilepsy, St Piers Lane, Lingfield, Surrey RH7 6PW

Professor Monica Lakhanpaul, Programme Director - Integrated Children, Young People and

Maternal Health Programme, UCL Partners, 170 Tottenham Court Road, London W1T 7HA

Dr Colin Dunkley, Consultant Paediatrician, Sherwood Forest Hospitals NHS Foundation Trust, King's

Mill Hospital, Mansfield Road, Sutton in Ashfield, Nottinghamshire NG17 4JL

Millie Power, Service User, London

Professor J Helen Cross, The Prince of Wales's Chair of Childhood Epilepsy and Honorary Consultant in Paediatric Neurology, UCL-Institute of Child Health \& Great Ormond Street Hospital for Children, London WC1N 1EH and Young Epilepsy, St Piers Lane, Lingfield, Surrey RH7 6PW

Licence statement: The Corresponding Author has the right to grant on behalf of all authors and does grant on behalf of all authors, an exclusive licence (or non-exclusive licence for UK Crown and US Federal Government employees) on a worldwide basis to the BMJ Publishing Group Ltd, and its Licensees to permit this article (if accepted) to be published in Archives of Disease in Childhood and any other BMJPGL products and to exploit all subsidiary rights, as set out in our licence.

Contributorship statement: $A B, J H C$ and $J C$ conceived this article. $A B$ and $D H$ led the writing of the main manuscript, and MP led the writing of the case study. All authors critically revised the manuscript and contributed to the article. $A B$ is the guarantor and corresponding author.

Competing interests: None declared

Funding statement: This research received no specific grant from any funding agency in the public, commercial or not-for-profit sectors. 


\section{References}

\footnotetext{
${ }^{1}$ WHO (2015) Global burden of epilepsy and the need for coordinated action at the country level to address its health, social and public knowledge implications http://apps.who.int/gb/ebwha/pdf_files/EB136/B136_CONF4-en.pdf (accessed 18th April 2015)

2 Poduri, A., \& Lowenstein, D. (2011). Epilepsy genetics - past, present, and future. Current opinion in genetics \& development, 21(3), 325-332.
}

${ }^{3}$ Téllez-Zenteno, J. F., Dhar, R., \& Wiebe, S. (2005). Long-term seizure outcomes following epilepsy surgery: a systematic review and meta-analysis. Brain, 128(5), 1188-1198.

${ }^{4}$ Levy, R. G., Cooper, P. N., Giri, P., \& Pulman, J. (2012). Ketogenic diet and other dietary treatments for epilepsy. Cochrane Database of Systematic Reviews, Issue 3

${ }^{5}$ WHO (2003) Global Campaign against Epilepsy: Out of the Shadows

http://www.who.int/mental_health/management/en/GcaeBroEn.pdf?ua=1 (accessed 18th April 2015)

${ }^{6}$ WHO (2004) Epilepsy in the Western Pacific Region: A call to action

http://www.who.int/mental_health/neurology/epilepsy/wpro_report.pdf?ua=1 (accessed 18th April 2015)

${ }^{7}$ WHO (2013) Follow-up to the Political Declaration of the High-level Meeting of the General Assembly on the Prevention and Control of Non-communicable Diseases, http://apps.who.int/gb/ebwha/pdf files/WHA66/A66 R10-en.pdf?ua=1 (accessed $18^{\text {th }}$ April 2015)

${ }^{8}$ Joint Epilepsy Council of the UK and Ireland (2011) Epilepsy prevalence, incidence, and other statistics, http://www.jointepilepsycouncil.org.uk/resources/publications.html (accessed 4th April 2015)

${ }^{9}$ Uldall P, Alving J, Hansen LK, Kibaek M, Buchholt J. (2006) The misdiagnosis of epilepsy in children admitted to a tertiary epilepsy centre with paroxysmal events. Arch Dis Child;91:219-21.

${ }^{10}$ White, C. (2001). “Doctor referred to GMC after inquiry into epilepsy diagnoses” BMJ, 323(7325), 1323

${ }^{11}$ Hanna N J, Black M, Sander JWS, Smithson WH, Appleton R, Brown S, Fish DR (2002) The National Sentinel Clinical Audit of Epilepsy-Related Death: Epilepsy- Death in the shadows, The Stationery Office.

\footnotetext{
${ }^{12}$ British Paediatric Neurology Association (2003) A national approach to epilepsy management in children and adolescents, http://www.bpna.org.uk/training/epilepsymanage.pdf (accessed 4th April 2015)

${ }^{13}$ British Paediatric Neurology Association http://www.bpna.org.uk/pet/ (accessed 18th April 2015)
} 
${ }^{14}$ National Institute for Health and Clinical Excellence (2004) The epilepsies: the diagnosis and management of the epilepsies in adults and children in primary and secondary care, www.nice.org.uk/cg20 (accessed 12th April 2015)

${ }^{15}$ Scottish Intercollegiate Guidelines Network (2005) Diagnosis and management of epilepsies in children and young people: A national clinical guideline, http://www.sign.ac.uk/pdf/sign81.pdf (accessed 12th April 2015)

${ }^{16}$ National Institute for Health and Care Excellence (2013) Quality standard for the epilepsies in children and young people, http://www.nice.org.uk/guidance/qs27 (accessed 12th April 2015)

${ }^{17}$ Royal College of Paediatrics and Child Health (2013) Coordinating Epilepsy Care: a UK-wide review of healthcare in cases of mortality and prolonged seizures in children and young people with epilepsies. Child Health Reviews-UK, London: RCPCH

${ }^{18}$ Royal College of Paediatrics and Child Health (2012) Epilepsy12 National Report September 2012: United Kingdom collaborative clinical audit of health care for children and young people with suspected epileptic seizures, http://www.rcpch.ac.uk/system/files/protected/page/Epilepsy web.pdf (accessed 12th April 2015)

${ }^{19}$ Royal College of Paediatrics and Child Health (2014) Epilepsy12 National Report Round 2: United Kingdom collaborative clinical audit of health care for children and young people with suspected epileptic seizures, http://www.rcpch.ac.uk/system/files/protected/page/Epilepsy12\%20report\%202014\%20for\%20web.pdf (accessed 12th April 2015)

${ }^{20}$ Reilly C, Atkinson P, Das KB et al. (2014) A population based study of neurobehavioral comorbidities in children with active epilepsy. Pediatrics; doi:10.1542/peds.2013-3087

${ }^{21}$ Reilly C., Atkinson P., Das, K.B., Chin, R.F., Aylett, S.E., Burch, V., ...Neville, B.G. (2015). Factors associated with quality of life in active childhood epilepsy: A population-based study, European Journal of Paediatric Neurology, http://dx.doi.org/10.1016/j.ejpn.2014.12.022 (accessed 20th April 2015)

${ }^{22}$ Rosen R and Ham C (2008) Integrated Care: Lessons from evidence and experience. London: Nuffield Trust.

${ }^{23}$ Children and Families Act (2014)

http://www.legislation.gov.uk/ukpga/2014/6/pdfs/ukpga 20140006 en.pdf (accessed 4th April 2015)

${ }^{24}$ Department of Health (2013) The NHS Outcomes Framework 2014-15, https://www.gov.uk/government/uploads/system/uploads/attachment data/file/256456/NHS outcomes.pdf (accessed 4th April 2015)

${ }^{25}$ Ham C and Smith J (2010) Removing the policy barriers to integrated care in England, The Nuffield Trust

${ }^{26}$ Young Epilepsy (2015) Improving epilepsy care for children and young people: an integrated approach. Young Epilepsy, Publication No: 340

${ }^{27}$ RCPCH (2010) Not Just a Phase: A Guide to the Participation of Children and Young People in Health Services. RCPCH. 
${ }^{28}$ Weil, L. G., Lemer, C., Webb, E., \& Hargreaves, D. S. (2015). The voices of children and young people in health: where are we now? Archives of disease in childhood, 100(10), 915-917. 